Running head: Associative Repetition Priming

\title{
Associative repetition priming: A selective review and theoretical implications
}

\author{
René Zeelenberg \\ University of Amsterdam \\ Diane Pecher \\ Utrecht University \\ and \\ Jeroen G.W. Raaijmakers \\ University of Amsterdam
}

Send correspondence to:

René Zeelenberg

Psychology Department 


\author{
Indiana University \\ Bloomington, IN 47405 \\ USA \\ phone: 001-812-856-5217 \\ fax: 001-812-855-1086 \\ email: rzeelenb@indiana.edu
}




\section{A. Introduction}

An extensive body of research in the last two decades has shown that recent experiences can affect performance even when subjects are not instructed to remember these earlier experiences and even when subjects are not aware of these experiences. These so-called implicit memory phenomena are usually demonstrated by the repetition priming effect. Repetition priming refers to the finding that responses are faster and more accurate to stimuli that have been encountered recently than to stimuli that have not been encountered recently. For example, in a perceptual word identification task (Jacoby \& Dallas, 1981; Salasoo, Shiffrin \& Feustel, 1985) subjects can more often correctly identify the briefly flashed target word if they have recently studied the target than if they have not studied the target. Comparable effects have been obtained in tasks such as picture identification (e.g., Rouder, Ratcliff \& McKoon, 2000), word stem completion (e.g., Graf, Squire, \& Mandler, 1984) and lexical decision (e.g., Bowers \& Michita, 1998; Scarborough, Cortese, \& Scarborough, 1977), to name but a few.

The large majority of studies in the domain of implicit memory have concentrated on the effect of repeating stimuli in isolation. In the common repetition priming paradigm stimuli are presented one-by-one both during the study phase and the test phase. A question that has received relatively little attention is whether repetition priming can be obtained not only for single stimuli but also for pairs of stimuli. In other words, is there an advantage of repeating a stimulus pair over and above the effect of repeating the individual stimuli? Such an effect might be obtained if an associative bond between the members of a pair is formed (or strengthened) and if this bond is accessed at the time of test. Research in other domains of psychology indicates that associative relations between stimuli affects performance in a variety of tasks. For example, a large number of studies in the field of associative priming (e.g., Balota \& Lorch, 1986; Evett \& Humphreys, 1981; Meyer and Schvaneveldt, 1971; Neely, 1977) have shown that responses are faster and/or more accurate to targets that follow related words (e.g., lion-tiger) than to targets that follow unrelated words (e.g., sand-tiger). In a similar vein, a response to a target stimulus might be facilitated if the target is preceded by a stimulus with which it has been studied recently. A typical experiment investigating priming for pairs of words consists of study phase in which a list of word pairs (e.g., sand-tiger) is presented. The study phase is followed by a test phase in which word pairs are presented in a priming paradigm. In the priming task, the prime words are presented either immediately prior to the target word or simultaneously with the target word. Priming is assessed by comparing performance for prime-target pairs that were studied together during the study phase to performance for pairs that were not studied together. In the remainder of this chapter we will refer to such a priming effect due to the repetition of a stimulus pair as associative repetition priming. 1

As we will argue in this chapter, associative repetition priming is of interest not only from an empirical perspective, but also from a more theoretical perspective. In the second part of this chapter we will discuss some examples of how the finding of associative repetition priming can be used to answer some fundamental questions concerning the representation of knowledge in memory and the retrieval of knowledge from memory. More specifically, we will address three issues that have been raised in the literature. The first issue is whether or not the findings from the associative priming literature provide evidence supporting the hypothesis that there are separate episodic and semantic memory systems. Several researchers have proposed that associative repetition priming depends on the formation of new semantic traces. The most important difference between episodic and semantic memory is that episodic memories depend on the overlap in contextual information between study and test. Semantic memories on the other hand are assumed to be abstract and therefore contain no contextual information from the study 
episodes. By investigating the extent to which associative repetition priming is sensitive to contextual overlap between study and test we obtain evidence regarding the distinction between episodic and semantic memory.

The second issue is whether associative priming is subject to interference. Specifically, we will ask the question whether strengthening a word pair (e.g., lion-mane) interferes with priming for other word pairs (e.g., lion-tiger) sharing the same prime. This question touches on the fundamental issue whether activation processes in memory depend on relative or absolute associative strength (see M.C. Anderson \& Bjork, 1994, for a discussion of different accounts of interference). As we will discuss, this question is difficult to answer using other methods. One problem is that there is no adequate method of assessing the strengths of the associations between words in memory. The finding of associative repetition priming, however, allows us to manipulate the structure of the associative network and hence to address the question whether activation depends on relative or absolute associative strength.

A final issue concerns the question whether priming in the standard associative priming paradigm (i.e., priming for related pairs such as lion-tiger) depends on associative or on semantic relations between words. Some researchers (e.g., Shelton \& Martin, 1992) have argued that priming depends on associative relations between words that are the result of co-occurrence in natural language. Other researchers (e.g., Thompson-Schill, Kurtz, \& Gabrieli, 1998) have argued, however, that priming is not mediated by associative relations between words. According to these researchers, priming depends on semantic similarity which is usually defined as overlap in featural descriptions. We argue that the finding of associative repetition priming is problematic for those accounts proposing a strong distinction between associative and semantic relations, while arguing that associative relations do not cause priming.

It is important to first establish whether or not associative repetition priming in implicit memory tasks can be obtained before these theoretically more interesting questions can be answered. There is considerable disagreement among researchers whether or not truly implicit associative repetition priming occurs. Although associative repetition priming has been obtained in a number of studies (e.g., McKoon \& Ratcliff, 1979, 1986) these results have often been dismissed on the ground that they were due to contamination by explicit retrieval attempts. In the first part of this chapter we will review the existing literature on associative repetition priming. Contrary to what is argued by many researchers we will argue that there is convincing evidence to support the notion that automatic associative repetition priming can be obtained. In the second part of the chapter will discuss how associative repetition priming can be used as a tool to provide some new insights in the theoretical issues mentioned above.

\section{A. Associative repetition priming: a selective review of experimental results}

\section{B. Methodological issues}

Before we turn to a review of the literature we will discuss two methodological concerns that have been raised by researchers investigating associative repetition priming. The first concern is the possible contamination of associative repetition priming effects with explicit retrieval. The second concern is the choice of an appropriate baseline condition against which associative repetition priming can be assessed.

Studies that investigate associative repetition priming usually consist of some sort of study phase in which word pairs are studied. After the study phase, word pairs are presented in an implicit memory task. The question of interest is whether responses to the target word are facilitated by presentation of the prime word with which the target was presented during study. Associative repetition priming effects have been studied in a number of different tasks including word stem completion (Graf \& Schacter, 1987), lexical decision (Ratcliff \& McKoon, 1979) and 
perceptual identification (Pecher \& Raaijmakers, 1999). One complicating factor in the interpretation of associative repetition priming effects is that the effects might be due to contamination by explicit retrieval strategies (Carrol \& Kirsner, 1982; Durgunoglu \& Neely, 1987). The use of a word stem completion task in particular has been critized (see for example, Reingold \& Goshen-Gottstein, 1996) for its susceptibility to contamination by explicit retrieval strategies. In a word stem completion task word pairs (e.g., sand-tiger) are presented at study. At test the prime word is presented along with the word stem (i.e., sand-ti__). In an attempt to come up with a word to complete the stem subjects might try to remember the studied word pairs and hence the resulting priming effect could be due to contamination by explicit retrieval. In the present review of the literature we will therefore limit discussion to those studies that have used priming tasks such as lexical decision and perceptual identification in which contamination by explicit retrieval processes can be minimized or eliminated. ${ }^{2}$

It is important to note that the use of a priming task such as lexical decision in itself does not eliminate the use of explicit retrieval strategies that can cause priming effects. A large number of studies have been dedicated to investigate the nature of strategies that affect priming and the conditions under which these strategies occur in the 'standard' associative priming paradigm in which the effect of a semantically related prime on the processing of a subsequently presented target is investigated. One strategy that has been proposed is the predictive or expectancy-based generation strategy. The idea is that participants generate expectancies about the target after reading the prime (Becker, 1980; Neely, 1977; Posner \& Snyder, 1975) and that the response to the target will be facilitated if the target matches the expectancy of the participant. In standard associative priming experiments the expectancy that is generated will be a semantic associate of the prime (e.g., the subject will expect the target tiger after reading the prime lion), however, expectancies may also play a role in associative repetition priming. After reading the prime the participant may try to generate the target with which the prime was paired during study. If the target is indeed the word with which the prime was paired during study such a strategy might result in facilitation for recently studied word pairs.

It is generally assumed that expectancy-based strategies are effective only at longer SOAs (Stimulus Onset Asynchrony: the time interval between the onset of the presentation of the prime and the onset of the presentation of the target), when participants have enough time to generate expectancies (e.g., Neely, 1977; den Heyer, Briand \& Dannenbring, 1983). Therefore, the influence of these strategies can be eliminated by using a short SOA (i.e., an SOA of about 250 ms or shorter). Because the present paper is concerned primarily with fast-acting automatic priming we will focus on those experiments in which a short SOA was used although we will occasionally discuss results from experiments that used a longer SOA.

The second concern is the choice of an appropriate baseline condition. In order to determine whether study of a word pair results in associative repetition priming, performance in an intact condition (e.g., study: sand-tiger, test: sand-tiger) must be compared with performance in a control condition. Table 1 shows three different control conditions that have been used in studies that have investigated associative repetition priming. The first is a control condition in which a studied target is combined with a neutral prime such as the letterstring $x x x$ or the word blank. The use of a neutral prime is potentially problematic, because a neutral prime differs in many respects from the prime in the intact condition. First, neutral primes have no $(x x x)$ or little (blank) meaning and are (in the case of $x x x$ ) orthographically less complex than prime words in the experimental condition. Second, neutral primes are usually not presented during the study phase. Third, during the test phase, the same neutral prime is used for all targets in the neutral condition while the primes in the experimental condition are unique for each target. Thus, during 
the test phase, the neutral prime is repeated whereas the prime in the intact condition is presented only once. All these differences between a neutral prime and the prime in the intact condition could potentially affect performance to the target and hence cause a difference in performance between the intact condition and the neutral condition. ${ }^{3}$ Such a difference would not be due, however, to the associative relation between the prime and target in the-intact condition but to differences in the processing of the primes between the intact and neutral conditions.

A similar problem occurs for a baseline with nonstudied primes. In that case, the baseline consists of studied targets that are preceded by primes that were not presented during study. Because the primes in the experimental condition are studied, this nonstudied prime condition, like the neutral condition, has the problem that the study status of the prime is confounded with the associative relation between the prime and the target. Therefore we cannot be sure that a difference between the intact condition and the control condition is due to repetition of the association. In fact, any difference could potentially be due to a difference in the study status of the prime between the two conditions. A study by Smith, MacLeod, Bain, and Hoppe (1989) shows that this concern is not purely hypothetical and that the study status of the prime can affect response times to the target. Smith et al. obtained a so-called list wide priming effect. Responses were faster to studied targets that were preceded by a studied prime than to studied targets preceded by a nonstudied prime, irrespective of whether or not the studied prime and studied target were presented together (i.e., as a pair) during study.

We argue that to make the claim that associative repetition priming is obtained, the use of a recombined condition is preferable. In the recombined condition both the prime and target are presented during study although not as members of the same pair. This ensures that repetition status for individual words is identical for the intact condition and the control condition and that any difference between the two conditions is due to the repetition status of the pair. We will now turn to a selective review of empirical results related to the phenomenon of associative repetition priming.

B. Does automatic associative repetition priming exist?

We have identified fourteen studies that have investigated associative repetition priming in paradigms that used a relatively short SOA so that the possibility of contamination by predictive strategies was minimized. As we will show, studies that have investigated associative repetition priming have produced somewhat mixed results. Several studies reported in the literature have failed to obtain consistent evidence for associative repetition priming and this has lead researchers to argue that automatic associative repetition priming does not occur. However, as we will argue, in most of these studies there are alternative explanations for the absence of associative repetition priming. Thus, our conclusion is that the currently available data support the notion that automatic associative repetition priming can be obtained.

C. Early evidence for associative repetition priming: McKoon and Ratcliff (1979, 1986) The first study, to our knowledge, that investigated associative repetition priming was performed by McKoon and Ratcliff (1979). They used a repeated study-test procedure in which subjects studied short lists of paired-associates (e.g., city-grass) that were immediately followed by short lists of lexical decision trials with words presented one at a time. McKoon and Ratcliff obtained consistent evidence for associative repetition priming. Several researchers (Carrol \& Kirsner, 1982; Durgunoglu \& Neely, 1987; Goshen-Gottstein \& Moscovitch, 1995b) have, however, argued that interpretation of the results is problematic because of methodological problems and that therefore the results do not unambiguously support the hypothesis that automatic associative repetition priming can be obtained. 
One problem mentioned by those who criticized the McKoon and Ratcliff study is that the SOA was relatively long and that therefore the effect could be due to strategic recollective processes (i.e., predictive strategies). McKoon and Ratcliff used a continuous presentation paradigm in which participants respond by making a lexical decision to each stimulus in a long continuous sequence of stimuli. In this paradigm the stimulus on the previous presentation acts as a prime for the stimulus on the current presentation. McKoon and Ratcliff used a $250 \mathrm{~ms}$ and a $150 \mathrm{~ms}$ response stimulus interval (i.e., the time between the response to the stimulus on trial $n-1$ and the onset of the presentation of the stimulus on trial $n$ ) in Experiments 1 and 2, respectively. Since response times were in the order of 550-600 ms this means that the nominal SOA was about 700-850 ms. It should be noted, however, that although the nominal SOA was indeed quite long it is difficult to compare it to the SOA in a standard presentation procedure in which a prime is briefly presented and followed by a target. The task demands are quite different in both tasks because in the standard paradigm subjects do not respond to the primes. To our knowledge, there are no available data that show that subjects use a predictive strategy in a continuous presentation paradigm. Thus, it is an open question whether under the conditions used by McKoon and Ratcliff (1979) subjects were able to employ predictive strategies. More important, in Experiment 3 McKoon and Ratcliff (1979) used a standard presentation procedure with a $300 \mathrm{~ms}$ SOA and again obtained an associative repetition priming effect. In order to provide further evidence against the claim that associative repetition priming depends on predictive strategies McKoon and Ratcliff (1986) performed a follow-up study in which they used a standard presentation paradigm with an even shorter SOA (i.e., 150-250 ms). In a series of experiments they consistently obtained evidence for associative repetition priming. Because associative repetition priming was obtained at a short SOA these results can not easily be attributed to predictive strategies.

A second problem mentioned by some researchers (e.g., Goshen-Gottstein \& Moscovitch, $1995 \mathrm{a})$ is that the McKoon and Ratcliff studies $(1979,1986)$ confounded associative repetition priming and standard associative priming. McKoon and Ratcliff chose the word pairs in the intact condition so that they would be easy to learn (e.g., city-grass, angel-nurse), but not associated according to free association norms. Although McKoon and Ratcliff used a recombined control condition, the intact and control condition were not completely counterbalanced. Thus, in the intact condition the word pair angel-nurse would be presented both at study and at test. In the recombined control condition, however, the word pairs table-house and paper-nurse would be presented at study and the recombined word pair table-nurse would be presented at test. Thus, the word pairs in the intact and control condition were not identical and therefore the difference between the intact condition and the recombined condition might have been due to a weak pre-existing relation between the prime and target in the intact condition instead of to a newly learned association (i.e., the 'associative repetition' priming effect might in fact have been a disguised standard associative priming effect). However, this possibility was ruled out by Experiment 3 of the McKoon and Ratcliff (1979) study that showed that a priming effect was obtained only for studied pairs and not for nonstudied pairs (i.e., the priming effect was due to the recent study of the word pair and not to a pre-existing relation between the prime and the target). To summarize, the studies of McKoon and Ratcliff seem to provide solid evidence for automatic associative repetition priming.

C. Evidence against automatic associative repetition priming?

As we mentioned earlier, the conclusion of McKoon and Ratcliff (1979) that automatic associative repetition priming can be obtained has been questioned by several researchers. In a number of studies that followed the McKoon and Ratcliff (1979) study researchers have failed to 
obtain consistent evidence for associative repetition priming. In one such a study Carroll and Kirsner (1982) presented word pairs in a lexical decision task. Each prime and target were presented twice. On the second presentation word pairs were either intact (i.e., the same pairing as on the previous presentation) or recombined (i.e., a different pairing). Carrol and Kirsner obtained significant associative repetition priming for intact pre-experimentally related word pairs (e.g., lion-tiger) but not for intact pre-experimentally unrelated word pairs (e.g., sand-tiger).

In another study, Den Heyer (1986) presented word pairs six times in a lexical decision task and observed that the associative repetition priming effect for repeated pairs depended on the SOA used in the experiment. Den Heyer obtained priming for repeated pairs compared to a neutral condition (in which the prime was the word blank) at a long SOA (550 ms) was used, but not at a short SOA $(100 \mathrm{~ms})$ and argued that the different results might be due to the use of predictive strategies at a long SOA. However, as we argued the use of neutral primes as a baseline is problematic. In one experiment, Den Heyer studied associative repetition priming with a recombined control condition using a long SOA and obtained a significant priming effect for both related and unrelated intact pairs. Unfortunately, Den Heyer did not use a recombined control condition at a short SOA. Therefore the results of this study are difficult to interpret.

Neely and Durgunoglu (1985) and Smith et al. (1989) also studied associative repetition priming, but contrary to the above mentioned studies used a paired-associate learning task during study. This made their study procedures more similar to those used by McKoon and Ratcliff (1979, 1986). However, both Smith et al. and Neely and Durgunoglu failed to find any evidence for associative repetition priming. Durgunoglu and Neely (1987) did obtain associative repetition priming but only under very specific conditions. Durgunoglu and Neely studied associative repetition priming at both a short $(150 \mathrm{~ms})$ SOA and a long $(950 \mathrm{~ms})$ SOA. We limit discussion to the results obtained at a short SOA. Durgunoglu and Neely manipulated a number of factors that might affect the occurrence of associative repetition priming and only obtained associative repetition priming when all word targets had been studied during the study phase and all nonwords had not been studied during the study phase (i.e., when there was perfect confounding between the study status and lexical status of the stimuli). This finding was attributed to a decision bias. Durgunoglu and Neely argued that the confounding of episodic status and lexical status encouraged participants to use episodic information in making a lexical decision to the target. For targets recognized as being presented during the study phase the participant would be biased towards a 'word' response and for targets not recognized as being presented during the study phase the participant would be biased towards a 'nonword' response.

In a further attempt to obtain associative repetition priming Dagenbach, Horst and Carr (1990) presented word pairs in a very long study phase. Word pairs were studied extensively, especially in Experiments 3 and 4 in which word pairs were presented in a study phase that lasted 5 weeks. Every week subjects visited the lab and studied the same word pairs until they could correctly recall all pairings (i.e., until they could produce the target word upon presentation of the prime). This was followed by 10 additional practice trials for each word pair. Furthermore, during each week, between their visits to the lab, subjects were required to make sentences using the two words of the pair in a meaningful way. Dagenbach et al. obtained associative repetition priming only in Experiment 3 in which the primes were new unfamiliar words (i.e., very low frequency words that were not known to most subjects) learned in the experiment and the targets were familiar synonyms of the primes (e.g., drupe-cherry). In Experiment 4 using unrelated word pairs consisting of familiar words (e.g., sand-tiger) no significant associative repetition priming was obtained. 
The studies just described all failed to obtain consistent evidence for associative repetition priming. A few remarks are in order, however, when evaluating these studies since the evidence against associative repetition priming provided by these studies is not as solid as it might seem at first sight. First, the studies of Carrol and Kirsner (1982) and Dagenbach et al. (1990) did not obtain significant associative repetition priming for semantically unrelated primetarget pairs (e.g., sand-tiger), but they did obtain associative repetition priming for semantically related prime-target pairs (e.g., lion-tiger). Thus, they did obtain some evidence for associative repetition priming. Moreover, even for semantically unrelated pairs there was an effect in the expected direction in both the Carrol and Kirsner and the Dagenbach et al. studies. However, given that the number of observations were quite small in both studies (12 observations per condition in both studies and only 14 subjects in the Carrol and Kirsner study and 12 subjects in the Dagenbach et al. study) the power to detect an effect was probably not very high.

Smith et al. (1989) failed to obtain associative repetition priming at both a short and a long SOA. Although we have not been able to come up with a good explanation for their failure to obtain an effect, the absence of associative repetition priming in their study at a long SOA is somewhat troublesome because other researchers (den Heyer, 1986, Durgunoglu \& Neely, 1987) that did not obtain associative repetition priming at a short SOA obtained at least some indication of such an effect at longer SOAs.

Durgunoglu and Neely (1987) performed a large number of experiments and as mentioned above obtained evidence for associative repetition priming only under a limited set of conditions. It should be noted, however, that in none of the experiments they succeeded in obtaining standard associative priming (i.e., priming for semantically related prime-target pairs such as lion-tiger) at a short SOA. The absence of standard associative priming is quite puzzling and indicates that one should be cautious interpreting the absence of associative repetition priming in this study.

To conclude, the studies discussed in this section are often cited as providing evidence against the notion of automatic associative repetition priming. We argue, however, that failure to find consistent evidence for associative repetition priming might have been due to methodological problems and do not provide convincing evidence against the occurrence of automatic associative repetition priming. We will now turn to more recent studies that succeeded in obtaining associative repetition priming.

C. Recent evidence for associative repetition priming

Goshen-Gottstein and Moscovitch (1995b) argued that automatic associative repetition priming can be obtained but that it depends on the preservation of the presentation format between study and test. During study, pairs of words were presented and subjects were asked to form sentences with the two words of each pair. During test, the words of a pair were presented simultaneously, and subjects responded 'yes' if both words were existing words and 'no' otherwise. With this procedure Goshen-Gottstein and Moscovitch (1995a, Experiment 1) obtained associative repetition priming for pre-experimentally unrelated pairs. Encoding instructions during study did not affect associative repetition priming: under both shallow (vowel counting) and deep (sentence generation) instructions an associative repetition priming effect was obtained. In Experiment 2 (Goshen-Gottstein \& Moscovitch, 1995a), the presentation procedure at test was changed so that the prime and the target were presented sequentially. As in Experiment 1, subjects decided if both words (i.e., the prime and the target) were existing words or not. Consistent with the idea that preservation of the perceptual format is important, no associative repetition priming was obtained when the prime and target were presented sequentially at test. Another experiment (Goshen-Gottstein \& Moscovitch, 1995b, Experiment 1) provided further 
evidence that preservation of the perceptual format affects associative repetition priming. At test word pairs were presented visually and associative repetition priming was present for word pairs that were also presented visually during study but absent for word pairs that were presented auditorily during study. In sum, the experiments of Goshen-Gottstein and Moscovitch show that reliable associative repetition priming can be obtained after a single study trial if the perceptual format is maintained from study to test.

In our lab we have obtained associative repetition priming in a variety of priming tasks. The experiments in our lab differ from most other studies in that word pairs are usually presented multiple times during the study phase. In most of our experiments word pairs are presented in both an explicit paired-associate learning task and in a priming task (e.g., lexical decision) during study. At test, responses to intact studied pairs are compared to a baseline of recombined pairs. We have been especially concerned with using procedures to prevent strategies that might influence the associative repetition effect. In addition to lexical decision we have also investigated associative repetition priming in perceptual identification and animacy decision. This was done because some researchers have argued that 'standard' associative priming effects might be (partially) due to a so-called relatedness checking strategy, even with a short SOA (Balota \& Lorch, 1986; Shelton \& Martin, 1992). That is, in the lexical decision task, subjects make a binary decision about the lexical status of the target stimulus. An important characteristic of the primed lexical decision task is that there is a correlation between the relatedness of prime and target and the correct response. If the prime and target are semantically related the target must be a word, because nonwords are not related to words. The relatedness checking strategy account assumes that subjects use this correlation in the decision process. Subjects will be biased to give a 'word' response if they detect a relation between prime and target. It is further assumed that the absence of a relation will bias subjects to give a 'nonword' response. A similar strategy might play a role in producing associative repetition priming when there is a correlation between the study status of a word pair and the response. As we mentioned earlier, consistent with such a strategy, Durgunoglu and Neely (1987) obtained associative repetition priming only when there was a confounding between the study status and lexical status of the stimuli (i.e., when all words were studied and all nonwords were not studied). 4

In a number of recent studies we have investigated associative repetition priming in tasks in which the influence of possible relatedness checking strategies is eliminated. One such a task that we have used is the animacy decision task. In this task subjects decide whether a word refers to a living entity (e.g., tiger) or a nonliving entity (e.g., sand). The presentation procedure in this task is similar to that of lexical decision. In one study (Pecher \& Raaijmakers, 2001) we used a $260 \mathrm{~ms}$ SOA and responses were made to the target (but not to the prime). Relatedness checking strategies are not effective in an animacy decision task, because relatedness is not correlated with the response to the target. That is because related word pairs can be animate (doctor-nurse), inanimate (thread-needle), or mixed (baker-bread, school-teacher). Consequently a relation between prime and target gives no information about which response should be given (see McRae, de Sa, \& Seidenberg, 1997, for a similar argument). The same applies to studied word pairs. Targets of studied word pairs can be animate or inanimate, hence study status and response are not confounded. We obtained associative repetition priming in several experiments using the animacy decision task (Pecher \& Raaijmakers, 2001).

Another task that we used is masked perceptual identification. Our presentation procedure was based on the four-field paradigm developed by Evett and Humphreys (1981). In this paradigm four stimuli are presented on each trial: a forward pattern mask, the prime, the target, and a backward pattern mask. The task of the subject is to try to identify both the prime and 
target. However, subjects are usually unable to identify the prime. The presentation time is adjusted individually and set at a duration at which the subject can correctly identify the target on approximately $40 \%$ of the trials. In this task a standard associative priming effect is obtained: the probability of correctly identifying the target is higher if it is preceded by an associatively related prime than if preceded by an unrelated prime. This priming effect is not likely contaminated by strategies because the prime is masked (Pecher, Zeelenberg, \& Raaijmakers, 2001 obtained experimental evidence supporting this claim). Using the perceptual identification task we also obtained an associative repetition priming effect (Pecher \& Raaijmakers, 1999; Zeelenberg, 1998, Chapter 3). These results from the animacy decision and the perceptual identification experiments provide additional evidence that associative repetition priming can be obtained under conditions that eliminate contamination by explicit retrieval strategies.

In a series of experiments Schrijnemakers and Raaijmakers (1997), and Pecher and Raaijmakers (1999) studied whether there was transfer of associative repetition priming from a particular study task to another test task. Schrijnemakers and Raaijmakers (1997, Experiment 3) presented prime-target pairs nine times distributed over three different sessions with time intervals of 1 or 2 days. On each presentation the subject first made a lexical decision to the target, and then studied the complete word pair for a later cued recall test. At the end of the experiment associative repetition priming was tested in both lexical decision and perceptual identification. Schrijnemakers and Raaijmakers observed associative repetition priming in both tasks. However, only for the pre-experimentally unrelated word pairs did they use the correct recombined baseline. Therefore, Pecher and Raaijmakers (1999, Experiment 1) tried to replicate their results, this time using a recombined baseline for all types of word pairs. They obtained associative repetition priming only for pre-experimentally unrelated word pairs in lexical decision. In the perceptual identification task there was a small associative repetition priming effect, but it was only marginally significant. In Experiment 2, Pecher and Raaijmakers (1999) used a perceptual identification task during study. Word pairs were presented four times in the perceptual identification task and four times in a paired-associate study task. In the test phase, reliable associative repetition priming was obtained in perceptual identification but not in a lexical decision task with masked primes (although there was a small effect in the expected direction). In a recent study, Pecher and Raaijmakers (2001) used an animacy decision task at study. During the study phase word pairs were presented in animacy decision, paired-associate study or both. They observed associative repetition priming only for word pairs that had been presented in the animacy decision task during study, but not for word pairs that had been presented only in a paired-associate learning task. In sum, these experiments suggest that the associative repetition priming effect depends on the overlap in processes at study and test.

C. Concluding remarks regarding experimental findings

Our review shows that associative repetition priming has been obtained in a large number of experiments. Although associative repetition priming has not been obtained in every single experiment we have argued that in many such cases the absence of associative repetition priming might have been due to methodological problems. All in all there is plenty of evidence that associative repetition priming can be obtained under conditions in which it is unlikely that the results were due to contamination with explicit retrieval strategies. This is an important conclusion because many researchers have argued that associative repetition priming effects are the result of strategies.

Although we do argue that automatic associative repetition priming can be obtained, this is not to say, however, that the effects is as easy to find as 'standard' word repetition priming. Two factors may be important in obtaining associative repetition priming. The first factor is the 
amount of study given to a word pair in the study phase. We have generally been successful in obtaining associative repetition priming in our lab using multiple study trials. In other studies (with the exceptions of the studies by Dagenbach et al., 1989 and den Heyer, 1986) word pairs are presented only once. It seems reasonable to assume that the effect of prior study is larger after several study trials then after one study trial.

The second factor that may enhance the likelihood of finding associative repetition priming is the overlap between study procedure and test procedure. Goshen-Gottstein and Moscovitch (1995a, 1995b) showed that associative repetition priming was present when the spatio-temporal configuration of the word pair was identical at study and test. Associative repetition priming was obtained when both words of the pair were presented simultaneously at study and test, but not when they were presented simultaneously at study and sequentially at test. Associative repetition priming was also absent when the study modality changed from auditory presentation at study to visual presentation at test. ${ }^{5}$ In our lab we have always presented word pairs at study both in a paired-associate learning task as well as in a priming task (e.g., lexical decision). Our consistent success in obtaining associative repetition priming might be (partially) due to the presentation of the word pairs in the priming task. Consistent with this idea is the finding that the associative repetition priming effect is reduced when the priming task changed from study to test (Pecher \& Raaijmakers, 1999, 2001; Schrijnemakers \& Raaijmakers, 1997).

Goshen-Gottstein and Moscovitch concluded from their studies that associative repetition priming is perceptually based. According to their perceptual contiguity hypothesis associative repetition priming should be obtained only when the two words of a pair are presented simultaneously. However, in several studies (Pecher \& Raaijmakers, 1999, 2001; Zeelenberg, 1998) we did obtain reliable associative repetition priming, despite the fact that prime and target were presented sequentially. Thus, it is not the case that associative repetition priming relies solely on perceptual factors. Recently, we (Pecher \& Raaijmakers, 2001) have shown that semantic variables can also influence the associative repetition priming effect. In this experiment we studied associative repetition priming in an animacy decision task and manipulated the type of processing that was done during the study task. The study task focused on either semantic or on orthographic features of the word pairs, and we manipulated whether the study task was aimed at forming a unitized representation or not. Associative repetition priming was obtained only if the study task focused on semantic features and promoted forming a unitized representation of the prime-target pair. These results show the importance of the type of processing that is done during study for the occurrence of an associative repetition priming effect.

\section{A. Theoretical implications}

In the first part of this chapter we have reviewed the literature on associative repetition priming and concluded that associative repetition priming effects can be obtained even under conditions that eliminate contamination by explicit retrieval strategies. Our aim in the second part of this chapter is to indicate how the associative repetition priming effect might be used as a tool to find an answer to some theoretical questions that have been difficult to answer with other procedures.

B. The distinction between episodic and semantic memory

The associative repetition effect has been used to study how new information is added to semantic memory. There are basically two views on the storage of information in semantic memory. One is the multiple memory systems view, which assumes that semantic knowledge is stored separate from other types of knowledge such as episodic or procedural knowledge (Tulving, 1984; Tulving \& Schacter, 1990). These theories usually do not specify the exact processes that are involved in storing information, but the idea seems to be that whenever there is 
an experience, two separate memories are stored, one in episodic and one in semantic memory. Episodic memory consists of memories for specific events that are organized according to their temporal and spatial characteristics. Semantic memory consists of more abstract knowledge such as word meanings and the relations among words. Episodic memory is used in tasks such as recognition and recall, where explicit reference is made to the study episode. Semantic memory is used in tasks such as lexical decision, perceptual identification, or animacy decision, where there is no reference to the study episode. Another version of the multiple memory systems theory has distinguished yet another memory system, the perceptual representation system (Tulving \& Schacter, 1990). This system is assumed to be responsible for repetition priming or implicit memory effects. However, according to Tulving and Schacter, priming in conceptual tests is not explained by this system and thus has to be located in semantic memory.

The opposite view is that only one type of knowledge is stored in memory (J. R. Anderson \& Ross, 1980; Hintzman, 1986; McKoon, Ratcliff, \& Dell, 1986) and that more general or abstract information is calculated by the system as it is needed. For example, in Hintzman's model, a memory trace is stored for each experience. If an item, for example a word, is encountered several times it is stored on each occurrence together with some context features. If memory is probed with a cue that includes context, a specific trace that matches the context will be activated. However, if the cue only includes the word, all traces that contain the word are activated and the resulting content is more abstract (i.e., is averaged over different prior contexts). Thus, the system calculates more or less abstract information according to the cue that is used to access memory. There are no separate memory systems for episodic and semantic knowledge.

Dagenbach et al. (1990) studied associative repetition priming from the multiple memory systems view. They argued that associative repetition priming is found if these new associations have been added to semantic memory. They assumed that automatic priming in lexical decision is the result of associations in semantic memory and that automatic priming will not be found if the words are associated only in episodic memory. Thus, if priming is found for new associations, this is evidence that these new associations are integrated into semantic memory. McKoon and Ratcliff (1979, 1986), however, argued that if priming is found for new associations, this should be considered as evidence against the distinction between episodic and semantic memory. According to them if the two memory systems are separate it should be possible to access episodic and semantic information independently. Therefore, a semantic memory task such as lexical decision should not be affected by episodic information (i.e., there should be no priming for new associations). On the other hand, McKoon and Ratcliff argued that a theory that assumes that episodic and semantic information are stored in the same memory system does predict that both episodic and semantic information can affect performance in the same task.

The multiple memory systems view in which associative priming is mediated by the semantic system-predicts that the associative repetition effect should not be sensitive to context. It has been assumed that semantic memory is an abstraction of specific episodes, in other words, that semantic memory develops out of repeated experiences (Dagenbach et al., 1990). If information in semantic memory is abstract, retrieval should be context-independent. If a word is activated, its associates also become activated to some degree, and this should not depend on the context in which that word is presented. Similarly, information that is strongly related to a specific context should not be integrated into semantic memory. However, our results show that this is not always true. Our finding of automatic associative repetition priming in semantic memory tasks indicates that these new associations are integrated in semantic memory. Yet, we 
(Pecher \& Raaijmakers, 1999, 2001; Schrijnemakers \& Raaijmakers, 1997) found that prior context plays an important role in finding associative repetition priming. These results pose problems for theories that assume that semantic knowledge is abstract and does not contain information about the context in which it is encountered (Dagenbach, et al., 1990; Tulving, 1983, 1984). Rather, the results suggest that semantic memory does not consist of abstract information that is retrieved whenever a word is activated, but that it is more flexible. Storage and retrieval of information from semantic memory is dependent on the context in which a word is encountered. Other studies have also shown that both the present context (McKoon \& Ratcliff, 1995) and recent experiences with words (Dagenbach, Carr, Wilhelmsen, 1989; Pecher, Zeelenberg, \& Raaijmakers, 1998) affect what aspects of a word's meaning are activated at a certain moment.

We (Pecher \& Raaijmakers, 1999, 2001) have argued that associative repetition priming is obtained because the prime affects the interpretation of the target. Thus, for intact pairs the interpretation of the target is more similar at study and test than for recombined pairs. The task in which a word pair is presented will also affect this interpretation. If the word pair has been presented in the same task during study and test, the effect of the prime on the interpretation of the target during study is more relevant to the test task. In general, the more similar the study and test task are, the larger the overlap in interpretation of the target between study and test. Such a mechanism goes against the view of semantic memory as abstract and context-independent, and might be easier to accommodate into theories that do not make a distinction between semantic and episodic information.

B. Associative priming and interference

Interference effects have been obtained in a variety of memory tasks. The best known example is probably that of interference in paired-associate learning. In the retroactive interference paradigm participants first learn a list of A-B pairs. Participants in the interference group then learn a list of A-C pairs involving the same stimulus words as the pairs on the first list. For the participants in the control group the second list consists of C-D pairs having no stimulus words in common with the pairs on the first list. Participants are tested on their memory for the pairs on the first list. The stimulus term of each pair is presented and participants are required to produce the corresponding first-list response. Cued recall performance is typically lower for participants in the interference group than for participants in the control group (McGovern, 1964; also see Barnes \& Underwood, 1959). Although there are important differences between paired-associate learning and associative priming they are similar in that both depend on the existence of associations between words. An interesting question is whether interference effects analogous to those obtained in paired-associate learning are also obtained in associative priming.

The dominant theory of associative priming, the spreading activation theory does indeed predict such an interference effect. According to spreading activation theories (J. R. Anderson, 1983; Collins \& Loftus, 1975) words are represented by nodes in an associative network. The nodes representing related words are connected to each other by links. When a word is presented, the node representing that word is activated and activation spreads out in a parallel fashion along the links from the source node to related nodes. Associative priming occurs because the node representing the target receives activation from the node representing the prime. This results in an enhanced activation level of the target representation which speeds responding. In the ACT* model (J. R. Anderson, 1983), the amount of activation spreading from the source node to a related node depends on two factors, the strength of the node (which is a function of the number of presentations) and the number of other nodes connected to the source node. The stronger the association between two nodes A-B the more activation will spread from the source node A to the related node $\mathrm{B}$. The larger the number of other nodes that are connected to the source node 
and the larger the strength of these nodes the less activation will spread from A to B. Thus, spreading activation theories predict that the amount by which word A activates word $\mathrm{B}$ depends on the strength of the association A-B relative to all associations $\mathrm{A}-\mathrm{X}$.

The assumption that activation processes depend on relative associative strength is difficult to test in the context of associative priming because how are we to know the associative strengths in the network that supports the occurrence of priming? Associative strengths are usually inferred from free association norms. However, these norms are inherently based on the relative strength of the association. An example will help to explain the problem in assessing the absolute associative strength of a word pair. Suppose a word pair A-B has an association frequency of $25 \%$, that is in a free association task $25 \%$ of the participants respond with word B when asked to provide the first word that comes to mind when given the cue word A. Suppose another word pair D-E also has an association frequency of $25 \%$. Does this mean that the absolute associative strengths of both word pairs are identical? Not necessarily! The absolute associative strength of the word pair A-B might in fact be considerably stronger than that of D-E, but the association frequencies of A-B and D-E might be equally large because A-B has more or stronger competitors that D-E. In the example shown in Figure 1 the absolute associative strength A-B is 5 times larger than that of D-E (this might for example be due to the fact that the words of the pair A-B have been encountered more often in close proximity than the words of the pair D-E ). However, A-B has a stronger competitor than D-E. Free association does not reflect the absolute associative strength of an association because whenever a cue word is presented for free association multiple words might be activated. In order to emit a response one of the words has to be selected. Assuming that the probability of producing a certain word in free association depends on the strength of the association between the cue word (e.g., A) and the related word (e.g., B) relative to the other words (e.g., C) related to the cue, the probability of generating B to $\mathrm{A}$ is identical to that of generating $\mathrm{E}$ to $\mathrm{D}$ (i.e., $25 \%$ in both cases). Thus even though in the example the absolute associative strength of A-B is much larger than that of D-E, the association frequencies of $\mathrm{B}$ and $\mathrm{E}$ are identical. Thus, testing the relative strength assumption by using word pairs based on their association frequency is a troublesome enterprise.

An alternative approach to test the assumption that activation processes depend on relative associative strength is by manipulating the strengths in the associative network. The advantage of such an approach is that one has experimental control over the structure of the associative network and does not have to rely on measures of associative strength that are inherently based on the relative associative strength. We tested the relative strength assumption in a series of experiments. In our experiments, the interfering association A-C was strengthened in the study phase of the experiment. In the test phase, the effect of strengthening an interfering association on the priming effect for the test pair A-B was assessed. As a result of strengthening the association $\mathrm{A}-\mathrm{C}$ the relative strength of $\mathrm{A}-\mathrm{B}$ decreases. The prediction therefore is that if the activation process depends on relative associative strength the priming effect for the pair A-B (e.g., lion-tiger) should decrease if the association A-C (e.g., lion-mane) is strengthened.

We (Zeelenberg, 1998) tested the relative strength assumption in several experiments, using a lexical decision task with a short $200 \mathrm{~ms}$ SOA and a masked perceptual identification task. In both experiments a regular associative priming effect was found (i.e., performance was better for the word pair lion-tiger than for the pair sand-tiger). We also obtained an associative repetition priming effect (i.e., performance was better for repeated intact word pairs then for recombined word pairs). However, we did not obtain an interference effect. Thus strengthening the word pair lion-mane did not affect the priming effect for the pair lion-tiger. This finding is 
problematic for the claim that activation processes depend on the relative associative strength and seems to indicate that automatic activation processes depend on the absolute associative strength.

One might wonder how this finding might be reconciled with the finding of interference in a number of other paradigms. A detailed description of such an explanation is clearly beyond the scope of this chapter, but a brief discussion of it is in order. An important feature of this explanation is the distinction between activation and selection processes. Our explanation assumes that in many tasks performance does not directly reflect the activation level. For example, in a standard cued-recall task a stimulus cue (usually a word) is provided and the subject has to generate the word corresponding to the stimulus (i.e., the word with which the cue was paired during study). One problem the subject faces in a cued-recall task is that the cue might activate several words instead of only one, especially if the cue was studied with more than one response word as is the case in an interference paradigm. If it is assumed that one of the activated words must be selected for further processing (see for example Raaijmakers \& Shiffrin, 1981) then the fact that other words are associated with the cue will decrease the chance of selecting the correct word and hence impair performance. Such a decrease in performance does not, however, mean that the activation level of the words associated to the cue decreases. Instead if it is assumed that selection depends on the relative associative strength than the probability of selecting a particular word will decrease as more words are associated to the cue. Thus, there is no need to assume that the activation depends on relative associative strength.

In a priming task such as naming, lexical decision or perceptual identification the influence of selection processes is greatly reduced because subjects do not have to respond to the target on the basis of the prime information alone (which is the case in a task like cued-recall). Instead the target is presented and the subject has to respond to the target. The prime-target association may facilitate responding to the target, but the subject's task is to respond to the target and the associative relation does not have to be verified. Thus, on a theoretical level the absence of interference effects in associative priming is not inconsistent with the finding of interference in other paradigms. It suggests that activation processes are dependent on the absolute strength of associations, whereas selection processes are dependent on the relative strength.

The critical difference between the above proposal and spreading activation theory is the point in processing at which relative strength comes into play. In this respect it is useful to discuss a taxonomy proposed by M. C. Anderson and Bjork (1994) in some detail. Anderson and Bjork distinguished between resource diffusion models and occlusion models. In resource diffusion models such as ACT*, a limited amount of activation spreads out from the source node to related nodes. Strengthening an association results in more activation spreading from the source node to the strengthened node at the expense of less activation spreading to the other nodes. Thus, in resource diffusion models the relative strength exerts its influence at a very early stage in the retrieval process. Interference is, therefore, an almost inevitable prediction of resource diffusion models, because the cause of interference is located in a very early stage of processing. In occlusion models such as SAM (Mensink \& Raaijmakers, 1988; Raaijmakers \& Shiffrin, 1980), however, the cause of interference is located in a later stage of processing. In occlusion models, strengthening an association does not result in less activation going to nonstrengthened items. The 'bottleneck' in occlusion models is located in the competition for access to further processing mechanisms. If, however, the competition for access to further processing mechanisms is resolved by the test procedure then occlusion models need not predict interference. The absence of interference in our experiments is therefore not problematic for occlusion models, if it is assumed that the influence of selection processes was greatly reduced 
by our test procedures. Thus, the lack of interference effects in associative priming tasks suggests that the bottleneck is not in the activation of information in memory, but in the selection of items for further processing.

B. Priming and the distinction between associative and semantic relations Several researchers have made a distinction between associative or semantic relations between words. For example, according to Thompson-Schill, et al. (1998; see also Shelton \& Martin, 1992) associative relations, as measured by free association, reflect word use rather than word meaning. An associative relation between words may develop if two words co-occur relatively frequently in the use of language. It is further assumed that associative relations are represented at a lexical level of representation. Semantic relations on the other hand are assumed to reflect similarity in meaning or overlap in featural descriptions.

The distinction between associative and semantic relations has led to research investigating whether automatic priming is mediated by associative or semantic relations between words (Fischler, 1977; Lupker; 1984). Recently this issue has regained the interest of the field. Shelton and Martin (1992) reported automatic priming for associatively related word pairs (e.g., boy-girl) but not for semantically related word pairs that are not associated according to free association norms (e.g., nose-hand). They argued that semantic relations do not support automatic priming and that priming in the lexical decision task occurs at a lexical level of representation and not at a semantic level.

Thompson-Schill et al. (1998) disputed Shelton and Martin's (1992) claim that semantic relations do not support automatic priming. According to Thompson-Schill et al.:

a closer examination of their stimuli reveals an important confound in their experiments: the unassociated word pairs (e.g., "dirt-cement," "bird-fish," "duck-cow") seem to have far fewer semantic features in common than do the associated word pairs (e.g., "hillmountain," "blanket-sheet," "road-street"). In other words, the authors did not adequately equate semantic similarity in their two lists of stimuli. (p. 442)

Several other researchers (Lund, Burgess, \& Atchley, 1995; McRae \& Boisvert, 1998) have also disputed the conclusions of Shelton and Martin on the ground that in their study the associatively related pairs were more semantically similar than the semantically related but associatively unrelated pairs. The common claim of these researchers is that automatic priming effects can be based on semantic relations.

Thompson-Schill et al. (1998) went one step further and explicitly argued that automatic priming is mediated by semantic relations, but not by associative relations. This claim was based on the results of their Experiment 3. This experiment included word pairs that according to Thompson-Schill et al. were associatively related but semantically unrelated (e.g., foot-note). No priming was obtained for these word pairs. On the basis of these results, Thompson-Schill et al. concluded that a semantic relation between prime and target is not only sufficient to produce automatic priming, but that a semantic relation is necessary to produce automatic priming.

Unfortunately, the claim that associative relations are not sufficient to produce priming is not very convincing because of a methodological flaw, as is revealed by a closer look at their stimuli. We obtained the free association frequencies of the word pairs used by Thompson-Schill et al. (1998) from published free association norms (Nelson, McEvoy, \& Schreiber, 1994). The association norms showed that the word pairs in the associatively related but semantically unrelated condition were in fact not or only very weakly associated (the mean forward associative strength was .03 and the mean backward associative strength was .00). The semantically related 
word pairs had much stronger associations. These word pairs were unidirectionaly associated and had an mean associative strength of .38 (in either the forward or the backward direction). Thus, the Thompson-Schill et al. study was not a particularly fair test of the influence of associative relations on automatic priming. On the basis of these results, the conclusion that a semantic relation between prime and target is necessary to produce automatic priming is unwarranted.

The issue of whether associative or semantic relations support automatic priming is related to associative repetition priming because many researchers (e.g., Thompson-Schill et al., 1998) have argued that associative relations are based on co-occurrence. Therefore, if Thompson-Schill et al. are correct in their claim that associative relations do not support automatic priming effects associative repetition priming should not be obtained, especially not for pre-experimentally unrelated word pairs. The association between such a pair is mainly based on their co-occurrence in the study task, and not on semantic similarity. However, as we discussed earlier, there are now several studies that show that such effects can be obtained under conditions that are associated with automatic processes. Thus contrary to the claim of Thompson-Schill et al. there is ample evidence that associative relations support automatic priming.

\section{A. Summary and conclusions}

In the present chapter we have reviewed empirical studies on associative repetition priming. Although earlier findings of associative repetition priming have been attributed to explicit retrieval strategies we have argued that recent studies provide enough evidence to support the view that the repetition of word pair results in automatic priming. In the second part of the chapter we have provided some examples that show how the finding of associative repetition priming may be used to answer theoretical questions about the representations and processes involved in memory performance. We have shown how the associative repetition priming effect can be used to study the distinction between episodic and semantic memory. We have argued that although both the multiple memory systems view and the single memory systems view can explain associative repetition priming, the multiple memory systems view will have more difficulty doing so. Especially the influence of context is not a priori predicted by the multiple memory systems view. A second issue we have discussed was the role of relative and absolute associative strengths in priming tasks. The results suggest that whereas selection processes are dependent on relative associative strength, activation processes are dependent on absolute associative strength. Finally, we have argued that the finding of associative repetition priming is problematic for theories that make a strong distinction between semantic and associative relations and that argue that semantic relations support priming while associative relations do not support priming. 


\section{References}

Anderson, J. R. (1983). A spreading activation theory of memory. Journal of Verbal Learning and Verbal Behavior, 22, 261-295.

Anderson, J. R., \& Ross, B. E. (1980). Evidence against a semantic-episodic distinction. Journal of Experimental Psychology: Human Learning and Memory, 6, 441-466.

Anderson, M. C., \& Bjork, R. A.(1994). Mechanisms of inhibition in long-term memory: A new taxonomy. In D. Dagenbach \& T. Carr (Eds.) Inhibitory processes in attention, memory, and language (pp. 265-325), San Diego, CA: Academic Press.

Balota, D. A., \& Lorch, R. F. (1986). Depth of automatic spreading activation: Mediated priming effects in pronunciation but not in lexical decision. Journal of Experimental Psychology: Learning, Memory, and Cognition, 12, 336-345.

Barnes, J. M., \& Underwood, B. J. (1959). "Fate" of first-list associations in transfer theory. Journal of Experimental Psychology, 58, 97-105.

Becker, C. A. (1980). Semantic context effects in visual word recognition: An analysis of semantic strategies. Memory \& Cognition, 8, 493-512.

Bowers, J. S. \& Michita, Y. (1998). An investigation into the structure and acquisition of orthographic knowledge: Evidence from cross-script Kanji-Hiragana priming. Psychonomic Bulletin \& Review, 5 259-264.

Carroll, M., \& Kirsner, K. (1982). Context and repetition effects in lexical decision and recognition memory. Journal of Verbal Learning and Verbal Behavior, 21, 55-69.

Collins, A. M., \& Loftus, E. F. (1975). A spreading activation theory of semantic memory. Psychological Review, 82, 407-428.

Dagenbach, D., Carr, T. H., \& Wilhelmsen, A. (1989). Task-induced strategies and nearthreshold priming: Conscious influences on unconscious perception. Journal of Memory and Language, 28, 412-443.

Dagenbach, D., Horst, S., \& Carr, T. H. (1990). Adding new information to semantic memory: How much learning is enough to produce automatic priming? Journal of Experimental Psychology: Learning, Memory, and Cognition, 16, 581-591.

den Heyer, K. (1986). Manipulating attention-induced priming in a lexical-decision task by means of repeated prime-target presentations. Journal of Memory and Language, 25, 19-42.

den Heyer, K., Briand, K., \& Dannenbring, G. L. (1983). Strategic factors in a lexical decision task: Evidence for automatic and attention-driven processes. Memory \& Cognition, 11, 374-381.

Durgunoglu, A. Y., \& Neely, J. H. (1987). On obtaining episodic priming in a lexical decision task following paired-associate learning. Journal of Experimental Psychology: Learning, Memory, and Cognition, 13, 206-222.

Evett, L. J., \& Humphreys, G. W. (1981). The use of abstract graphemic information in lexical access. Quarterly Journal of Experimental Psychology, 33A, 325-350.

Fischler, I. (1977). Semantic facilitation without association in a lexical decision task. Memory \& Cognition, 5, 335-339.

Goshen-Gottstein, Y., \& Moscovitch, M. (1995a). Repetition priming effects of newly formed associations are perceptually based: evidence from shallow encoding and format specificity. Journal of Experimental Psychology: Learning, Memory, \& Cognition, 21, 12491262.

Goshen-Gottstein, Y., \& Moscovitch, M. (1995b). Repetition priming for newly formed and preexisting associations: perceptual and conceptual influences. Journal of Experimental Psychology: Learning, Memory, \& Cognition, 21, 1229-1248. 
Graf, P., \& Schacter, D. L. (1987). Selective effects of interference on implicit and explicit memory for new associations. Journal of Experimental Psychology: Learning, Memory, \& Cognition, 13, 45-53.

Graf, P., Squire, L. R., \& Mandler, G. (1984). The information that amnesic patients do not forget. Journal of Experimental Psychology: Learning, Memory, and Cognition, 10, 164-178.

Hintzman, D. L. (1986). "Schema abstraction" in a multiple-trace memory model. Psychological Review, 93, 411-428.

Jacoby, L. L., \& Dallas, M. (1981). On the relationship between autobiographical memory and perceptual learning. Journal of Experimental Psychology: General, 110, 306-340.

Jonides, J., \& Mack, R. (1984). On the cost and benefit of cost and benefit. Psychological Bulletin, 96, 411-428.

Lund, K., Burgess, C., \& Atchley, R. A. (1995). Semantic and associative priming in high-dimensional semantic space. Proceedings of the Cognitive Science Society (pp. 660-665). Hillsdale, NJ: Erlbaum Publishers.

Lupker, S. J. (1984). Semantic priming without association: A second look. Journal of Verbal Learning and Verbal Behavior, 23, 709-733.

McGovern, J. B. (1964). Extinction of associations in four transfer paradigms. Psychological Monographs, 78, (16, Whole No. 593).

McKoon, G., \& Ratcliff, R. (1979). Priming in episodic and semantic memory. Journal of Verbal Learning and Verbal Behavior, 18, 463-480.

McKoon, G., \& Ratcliff, R. (1986). Automatic activation of episodic information in a semantic memory task, Journal of Experimental Psychology: Learning, Memory, and Cognition, $12,108-115$.

McKoon, G., \& Ratcliff, R. (1995). Conceptual combinations and relational contexts in free association and in priming in lexical decision and naming. Psychonomic Bulletin \& Review, 2, 527-533.

McKoon, G., Ratcliff, R., \& Dell, G. S. (1986). A critical evaluation of the semanticepisodic distinction. Journal of Experimental Psychology: Learning, Memory, and Cognition, 12, 295-306.

McRae, K., \& Boisvert, S. (1998). Automatic semantic similarity priming. Journal of Experimental Psychology: Learning, Memory, and Cognition, 24, 558-572.

McRae, K., De Sa, V. R., \& Seidenberg, M. S. (1997). On the nature and scope of featural representations of word meaning. Journal of Experimental Psychology: General, 126, 99-130.

Mensink, G. J. M., \& Raaijmakers, J. G. W. (1988). A model for interference and forgetting. Psychological Review, 93, 434-455.

Meyer, D. E., \& Schvaneveldt, R. W. (1971). Facilitation in recognizing pairs of words: Evidence of a dependence between retrieval operations. Journal of Experimental Psychology, 90, 227-234.

Musen, G., \& Squire, L. R. (1993). On the implicit learning of novel associations by amnesic patients and normal subjects. Neuropsychology, 2, 119-135.

Neely, J. H. (1977). Semantic priming and retrieval from lexical memory: Roles of inhibitionless spreading activation and limited-capacity attention. Journal of Experimental Psychology: General, 106, 226-254.

Neely, J. H., \& Durgunoglu, A. Y. (1985). Dissociative episodic and semantic priming effects in episodic recognition and lexical decision tasks. Journal of Memory and Language, 24, 466-489. 
Nelson, D. L., McEvoy, C. L., \& Schreiber, T. A. (1994). The University of South Florida word association, rhyme, and word fragment norms. Unpublished manuscript.

Pecher, D., \& Raaijmakers, J.G.W. (1999). Automatic priming for new associations in lexical decision and perceptual identification. Quarterly Journal of Experimental Psychology, 52A, 593-614.

Pecher, D., \& Raaijmakers, J. G. W. (2001).Priming for new associations in animacy decision: Evidence for context-dependency. Manuscript submitted for publication.

Pecher, D., Zeelenberg, R., \& Raaijmakers, J. G. W. (20010). Associative priming in a masked perceptual identification task: evidence for automatic processes. Manuscript submitted for publication.

Pecher, D., Zeelenberg, R., \& Raaijmakers, J.G.W. (1998). Does pizza prime coin? Perceptual priming in lexical decision and pronunciation. Journal of Memory and Language, 38, 401-418.

Posner, M. I., \& Snyder, C. R. R. (1975). Facilitation and inhibition in the processing of signals. In P. M. A. Rabbit \& S. Dornic (Eds.), Attention and Performance V. (pp. 669-682). New York: Academic Press.

Raaijmakers, J. G. W., \& Shiffrin, R. M. (1981). Search of associative memory. Psychological Review, 88, 93-134.

Reingold, E. M., \& Goshen-Gottstein, Y. (1996). Separating consciously controlled and automatic influences in memory for new associations. Journal of Experimental Psychology: Learning, Memory, and Cognition, 22, 397-406.

Rouder, J. N., Ratcliff, R., \& McKoon, G. (2000). A neural network model of implicit memory for object recognition. Psychological Science, 11, 13-19.

Salasoo, A., Shiffrin, R. M., \& Feustel, T. C. (1985). Building permanent memory codes: Codification and repetition effects in word identification. Journal of Experimental Psychology: General, 114, 50-77.

Scarborough, D. L., Cortese, C., \& Scarborough, H. S. (1977). Frequency and repetition effects in lexical memory. Journal of Experimental Psychology: Human Perception and Performance, 3, 1-17.

Schrijnemakers, J. M. C., \& Raaijmakers, J. G. W. (1997). Adding new word associations to semantic memory: Evidence for two interactive learning components. Acta Psychologica, 96, 103-132.

Schacter, D. L., \& Graf, P. (1986). Preserved learning in amnesic patients: Perspectives from research on direct priming. Journal of Clinical and Experimental Neuropsychology, 8, 727743.

Shelton, J. R., \& Martin, R. C. (1992). How semantic is automatic semantic priming? Journal of Experimental Psychology: Learning, Memory, and Cognition, 18, 1191-1210.

Shimamura, A. P., \& Squire, L. (1989). Impaired priming for new associations in amnesia. Journal of Experimental Psychology: Learning, Memory, and Cognition, 15, 721-728.

Smith, M. C., MacLeod, C. M., Bain, J. D., \& Hoppe, R. B. (1989). Lexical decision as an indirect test of memory: Repetition priming and list-wide priming as a function of type of encoding. Journal of Experimental Psychology: Learning, Memory, and Cognition, 15, 11091118.

Thompson-Schill, S. L., Kurtz, K. L., \& Gabrieli, J. D. E. (1998). Effects of semantic and associative relatedness on automatic priming. Journal of Memory and Language, 38, 440-458.

Tulving, E. (1983). Elements of episodic memory. New York: Oxford Univ. Press. 
Tulving, E. (1984). Precis of Elements of episodic memory. Behavioral and Brain Sciences, 7, 223-268.

Tulving, E., \& Schacter, D. L. (1990). Priming and human memory systems. Science, 247, 301-306.

Zeelenberg, R. (1998). Testing theories of priming. Unpublished doctoral dissertation. University of Amsterdam. 
Notes

1 In previous research, associative repetition priming has often been termed episodic priming or priming for new associations. However, we prefer to use the term associative repetition priming (this term was to the best of our knowledge first used by Goshen-Gottstein \& Moscovitch, 1995b). The term episodic priming might seem to suggest that different mechanisms are responsible for semantic and episodic priming effects which is not necessarily the case. The term priming for new associations seems to suggest that associative repetition priming is studied only for pre-experimentally unrelated word pairs. However, in some studies priming due to the repetition of word pairs is studied for both pre-experimentally unrelated (e.g., sand-tiger) and pre-experimentally related (e.g., lion-tiger) word pairs.

2 Note that we do not argue that associative repetition priming in a task such as word stem completion is necessarily due to contamination by explicit retrieval strategies. However, because many researchers have argued that associative repetition priming effects are due to strategies we will focus on those studies that are least likely to be subject to this criticism.

3 A detailed discussion of the advantages and disadvantages of a neutral condition is beyond the scope of the present chapter. The reader is referred to Jonides and Mack (1984) for a review of possible problems in interpreting performance relative to a neutral condition.

4 It should be noted, however, that McKoon and Ratcliff (1979, Experiment 2) did find associative repetition priming even when nonwords were presented during study. Evidence obtained in our lab (Zeelenberg, 1998, Chapter 3) also shows that associative repetition priming can be obtained when there is no perfect correlation between the study status and lexical status of stimuli.

5 Note, however, that this study confounded modality of presentation and temporal aspects of the presentation because for the auditory presentation condition words were presented sequentially at study and simultaneously at test whereas for the visual presentation condition the words of a pair were presented simultaneously both at study and test. 
Table 1 Types of Conditions Used in Experiments Investigating Associative Repetition Priming

\begin{tabular}{llr}
\hline & \multicolumn{2}{c}{ Example } \\
\cline { 2 - 3 } Type of Condition & Study Pair & Test Pair \\
\hline $\begin{array}{c}\text { Experimental } \\
\text { Intact }\end{array}$ & sand-tiger & sand-tiger \\
Control & & \\
Neutral & house-tiger & xxx-tiger \\
Nonstudied Prime & house-tiger & sand-tiger \\
Recombined & $\begin{array}{l}\text { house-tiger } \\
\text { sand-chair }\end{array}$ & sand-tiger \\
& & \\
\hline
\end{tabular}



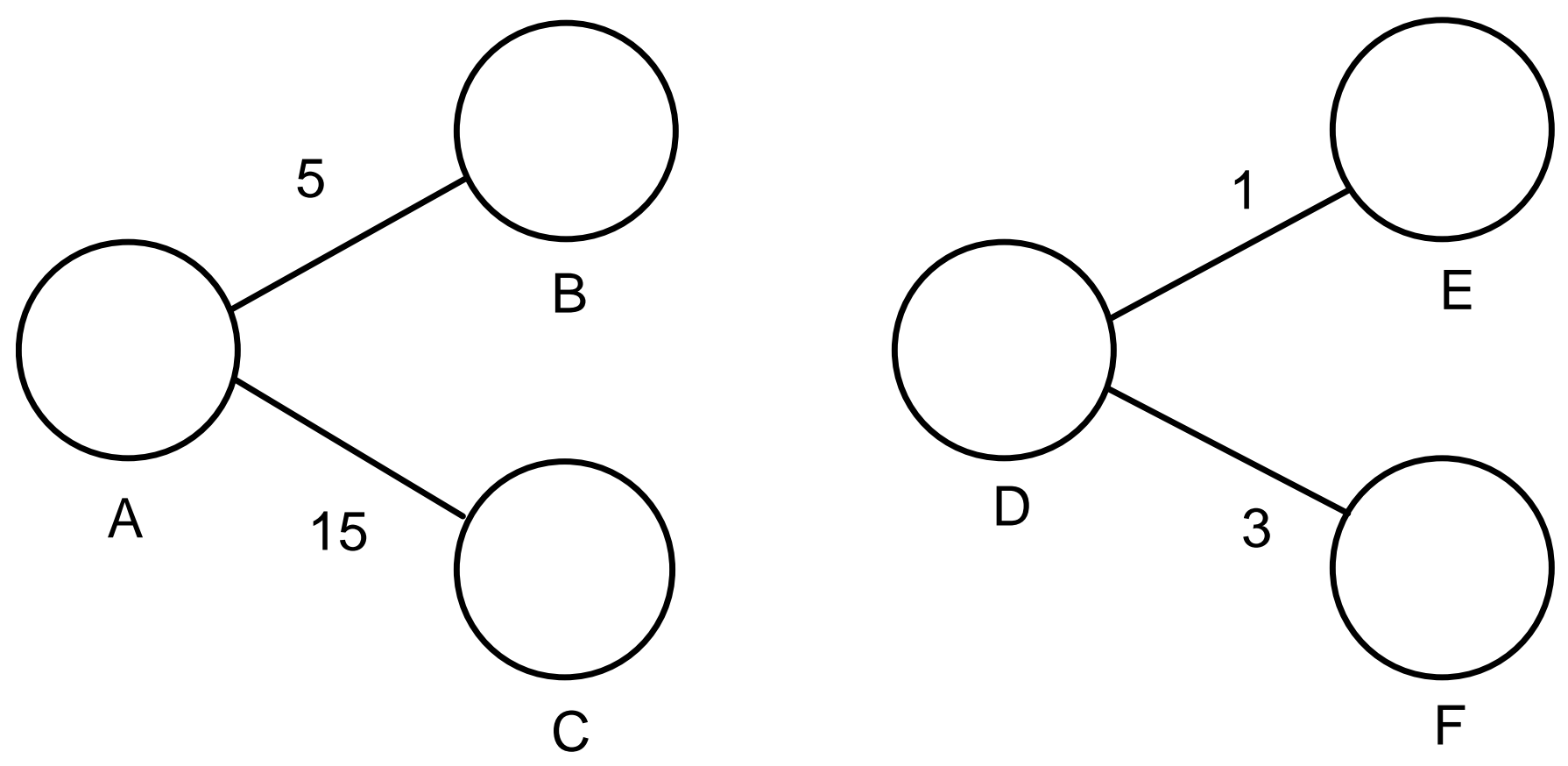

\section{Figure 1}

Example showing associative structures for word A, B, C and D, E, F. The numbers indicate the absolute associative strengths between two words. 